\title{
Different morphologies of carbon nanotubes effect on the lead removal from aqueous solution
}

\author{
Yan-Hui Li ${ }^{\text {a,b,*, }}$ Yanqiu Zhu ${ }^{\text {a }}$, Yimin Zhao ${ }^{\text {a }}$, Dehai Wu ${ }^{\mathrm{b}}$, Zhaokun Luan ${ }^{\mathrm{c}}$ \\ a Advanced Materials, School of Mechanical, Materials and Manufacturing Engineering, the University of Nottingham, University Park, \\ Nottingham NG7 2RD, UK \\ ${ }^{\mathrm{b}}$ Department of Mechanical Engineering, Tsinghua University, Beijing 100084, China \\ c State Key Laboratory of Environmental Aquatic Chemistry, Research Center for Eco-Environmental Sciences, Chinese Academy of Sciences, \\ Beijing 100085, China
}

Received 4 January 2005; accepted 6 July 2005

Available online 16 August 2005

\begin{abstract}
Four kinds of CNTs with different morphologies were produced by chemical vapour deposition method. After oxidation with nitric acid, their specific surface area, particle size distribution and functional groups on the surfaces were characterized. Adsorption isothermal experiment shows that the CNTs with more defects, which can be easily introduced more functional groups on their surfaces prepared at 650 ${ }^{\circ} \mathrm{C}$, have higher lead adsorption capability from aqueous solution and are promising adsorbents in wastewater treatment.

(C) 2005 Elsevier B.V. All rights reserved.
\end{abstract}

Keywords: Carbon nanotubes; Chemical vapour deposition; Defects; Adsorption

\section{Introduction}

Heavy metals, which most are toxic and harmful to human being as well as the fauna and flora, are enriched in wastewaters from battery manufacturing, painting, dying, photography, electroplating and other industries. One of them, lead is non-biodegradable and tends to bioaccumulate in cells of the living things. Long term drinking water containing lead even if in low concentration can cause many chronic or acute diseases, for example: fatigue, irritability, muscle weakness, convulsion possibly resulting in death and mental retardation in children. So it must be removed from the wastewater before being discharged into drainage system or drinking.

Many methods, including chemical precipitation, cementation, filtration, membrane separation, ion exchange,

\footnotetext{
* Corresponding author. Advanced Materials, School of Mechanical, Materials and Manufacturing Engineering, the University of Nottingham, University Park, Nottingham NG7 2RD, UK. Tel.: +44 115846 7257; fax: +44 1159513800 .

E-mail address: yanhui.li@nottingham.ac.uk (Y.-H. Li).
}

reverse osmosis and adsorption, have been developed and used to remove lead from wastewater. Adsorption is a widely used method because it is simple and cost-effective. Various adsorbents such as activated carbon [1,2], iron oxides [3], biomaterials [4], zeolites [5], manganese oxides [6], recycled alum sludge [7] and natural condensed tannin [8] have been studied, but low adsorption capacities or efficiencies limit their applications. Investigation of new adsorbents with higher adsorption capacities and efficiencies has been the aims of the researchers.

Carbon nanotubes (CNTs) have been the focus of research and development since their discovery due to their unique structures and exceptional properties. They have great potential applications in a wide range of areas such as microelectronic devices [9], field emission [10], catalyst supporter [11], chemical sensors [12], and as reinforcement in composites [13]. The larger specific surface area, the higher thermal and chemical stabilities, and the recent progress in large-scale synthesis with kilogram quantities [14] make CNTs attractively used as adsorbent materials. Much attention and effort have already been directed to adsorb gases such as hydrogen [15], ammonia [16], ozone 
[17], nitrogen, and methane [18] etc. by CNTs. Li et al. reported that CNT supported amorphous alumina had higher fluoride adsorption capability than that of AC-300 carbon [19]. After treatment with oxidants, CNTs also presented exceptional heavy metal adsorption capability from wastewater [20-22].

In this study we prepare CNTs with different morphologies and examine their lead adsorption properties from aqueous solution.

\section{Experimental}

Four kinds of CNTs with different morphologies used in this work were produced by chemical vapour deposition method. The detailed procedures in preparation were described in Refs. [19,23,24]. In brief, the samples Xylene-Fe- $800{ }^{\circ} \mathrm{C}$-Hor and Propylene-Ni-750 ${ }^{\circ} \mathrm{C}$-Hor were fabricated in a horizontal furnace. Their differences lie in that the sample Xylene-Fe- $800{ }^{\circ} \mathrm{C}$-Hor used a quartz tube (diameter $3 \mathrm{~cm}$ and $150 \mathrm{~cm}$ long). Plain quartz sheet was placed in the middle of the tube as supporter. As the temperature was heated to $800{ }^{\circ} \mathrm{C}$, the vapours of carbon source (xylene) and dissolved catalyst (ferrocene) were carried into reaction zone by $\mathrm{H}_{2}$ and $\mathrm{Ar}$ and produced aligned CNTs array supported on quartz sheet [23]. The sample Propylene-Ni-750 ${ }^{\circ} \mathrm{C}$-Hor adopted ceramic tube (diameter $5 \mathrm{~cm}$ and $150 \mathrm{~cm}$ long). The propylene-hydrogen mixtures were catalytic pyrolyzed at $750{ }^{\circ} \mathrm{C}$ using $\mathrm{Ni}$ particles as catalysts [19].

The samples Benzene-Fe- $1150{ }^{\circ} \mathrm{C}$-Vert and Methane-Ni$650{ }^{\circ} \mathrm{C}$-Vert were prepared in a vertical furnace. For the sample Benzene-Fe-1150 ${ }^{\circ} \mathrm{C}$-Vert, benzene was used as carbon source and dissolvent to dissolve catalysts of ferrocene and thiophene. The organic reactants were introduced in a vertical quartz tube (diameter $6.8 \mathrm{~cm}$ and $160 \mathrm{~cm}$ long) and reacted at $1150{ }^{\circ} \mathrm{C}$ under $\mathrm{H}_{2}$ atmosphere to produce CNTs [24]. For the sample Methane-Ni-650 ${ }^{\circ} \mathrm{C}$ Vert, the larger ceramic tube (diameter $30 \mathrm{~cm}$ and $80 \mathrm{~cm}$ long) was used. The catalysts of Ni particles were placed on ceramic boats. As the temperature reached $650{ }^{\circ} \mathrm{C}$, the methane and $\mathrm{H}_{2}$ were fed into the ceramic tube and CNTs were fabricated and deposited on the ceramic boats.

The as-grown CNTs were ground by ball milling to scatter the CNTs and refluxed with concentrated nitric acid at $140{ }^{\circ} \mathrm{C}$ for $1 \mathrm{~h}$ in order to remove the $\mathrm{Ni}$ catalyst particles and increase the functional groups on the surfaces of CNTs. Finally they were filtered with a ceramic filter to remove the acid and dried at $80{ }^{\circ} \mathrm{C}$ for the subsequent experimental use.

The specific surface area and pore size distributions of the four kinds of the oxidized CNTs were measured by nitrogen adsorption/desorption at $77 \mathrm{~K}$ using BET analyzer (Micromeritics ASAP 2000).

Particle size distributions of the oxidized CNTs were analyzed by laser light scattering with a Malvern Mastersizer (Mastersizer 2000). The suspensions of four kinds of
CNTs were prepared by dispersing $0.2 \mathrm{~g}$ CNTs into $100 \mathrm{ml}$ deionized water. The suspensions were supersonicated for 4 $\mathrm{h}$ to make CNTs scatter in water sufficiently. They were then added to the measurement cell under stirring until an obscuration between $10 \%$ and $20 \%$ were reached. The particle size distribution results were obtained.

To quantitatively estimate the functional groups on the surfaces of the oxidized CNTs, the Boehm's titration method was used [25]. The experiment procedures included dispersing $0.2 \mathrm{~g}$ of the three kinds of oxidized CNTs in $50 \mathrm{ml}$ deionized water. The suspensions were then mixed with $10 \mathrm{ml}$ of $0.1 \mathrm{M}$ base solutions of sodium hydroxide, sodium hydrogen carbonate and sodium carbonate and stirred in a sealed vessel for $48 \mathrm{~h}$. After this period, the suspensions were filtrated and $20 \mathrm{ml}$ filtrates were added to $15 \mathrm{ml}$ of $0.1 \mathrm{M}$ hydrochloric acid, which neutralized the unreacted bases. The solutions were then back-titrated with $0.1 \mathrm{M}$ sodium hydroxide using an Automatic Potential Titrator (716, Switzerland, Metrohm Co.), which recorded the volume of sodium hydroxide used to titrate the $\mathrm{pH}$ values of the solutions to 7.0.

Analytical grade lead nitrate was used to prepare a stock solution of $1000 \mathrm{mg} / \mathrm{l}$ of lead (II), which was further diluted to the required concentrations before using. All experiments were carried out at room temperature.

Adsorption isotherms were studied by adding $0.02 \mathrm{~g}$ of the four kinds of oxidized CNTs into $100 \mathrm{ml}$ solutions with initial concentrations of lead from 10 to $60 \mathrm{mg} / \mathrm{l}$ with a step value of $10 \mathrm{mg} / \mathrm{l}$. The $\mathrm{pH}$ values were adjusted and kept at 5.0. After the suspensions were shaken for $6 \mathrm{~h}$, they were filtered through a $0.45 \mu \mathrm{m}$ membrane filters. The filtrates were immediately measured by an atomic adsorption spectrometer. The amount of lead adsorbed on the CNTs was calculated by subtracting the equilibrium lead content from the initial lead content.

\section{Results and discussion}

Fig. 1 shows the TEM images of four kinds of the CNTs with different morphologies. It can be seen that the most of the CNTs in the sample Xylene-Fe- $800{ }^{\circ} \mathrm{C}$-Hor (Fig. 1a) are straight and their average diameters are about $60 \mathrm{~nm}$. For the sample Benzene-Fe-1150 ${ }^{\circ} \mathrm{C}$-Vert, the CNTs have an average diameter of 20-30 nm (Fig. 1b). Their bodies are relative straight and have little defects due to the higher preparation temperature. There are also thick fibers existed with diameters of $120 \mathrm{~nm}$ and in volume of $20 \%$. The average CNTs diameters of the sample Propylene-Ni-750 ${ }^{\circ} \mathrm{C}-\mathrm{Hor}$ are $30 \mathrm{~nm}$ (Fig. 1c). They are usually curved and entangled with each other, but their structures are quite integrated and graphite layers of the tube walls can be discerned clearly. The CNTs quality of the sample Methane-Ni-650 ${ }^{\circ} \mathrm{C}$-Vert is weak due to the higher quantity produced in one batch $(500 \mathrm{~g} / \mathrm{batch}$, the production of the other three kinds of the CNTs is $2 \mathrm{~g} /$ 

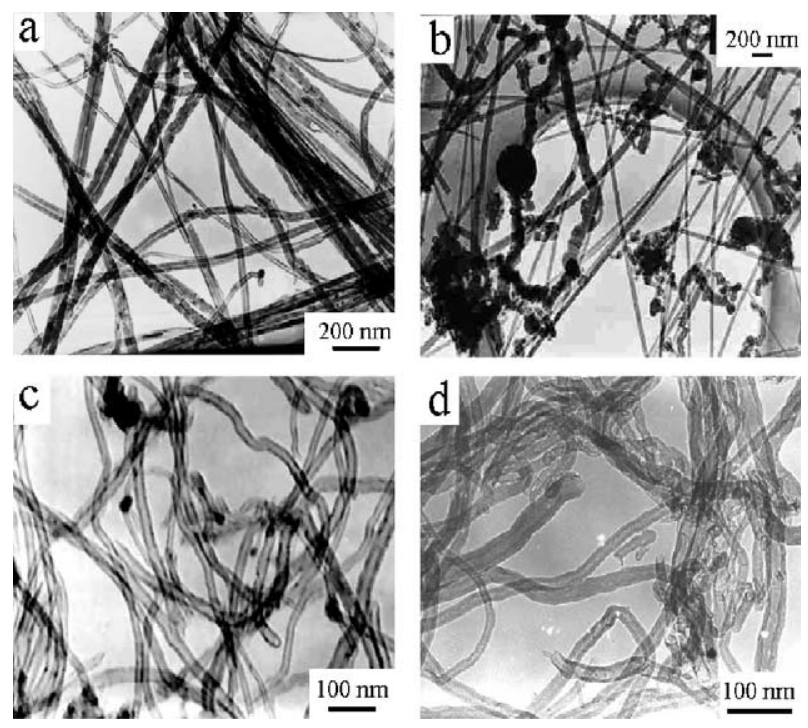

Fig. 1. The TEM images of four kinds of the as-grown CNTs with different morphologies. (a) Sample Xylene-Fe- $800{ }^{\circ} \mathrm{C}-\mathrm{Hor}$; (b) Sample Benzene-Fe$1150{ }^{\circ} \mathrm{C}$-Vert; (c) Sample Propylene-Ni-750 ${ }^{\circ} \mathrm{C}$-Hor; (d) Sample MethaneNi-650 ${ }^{\circ} \mathrm{C}$-Vert.

batch). Their average diameters are about $30 \mathrm{~nm}$. There are many defects existed on the walls of the CNTs and their layered structures are not perfect (Fig. 1d).

The specific surface area and pore volume of four kinds of the oxidized CNTs are compared in Table 1. The specific surface area and pore volume of the sample Xylene-Fe- 800 ${ }^{\circ} \mathrm{C}-$ Hor is $47 \mathrm{~m}^{2} / \mathrm{g}$ and $0.18 \mathrm{~cm}^{3} / \mathrm{g}$, respectively. This may attribute to their larger diameters $(60 \mathrm{~nm})$ and straighter tube bodies, which make it difficult to break up the CNTs into smaller pieces due to the high crystallization degree and little defects on the surfaces of the CNTs. Although the CNTs diameters of the sample Benzene-Fe- $1150{ }^{\circ} \mathrm{C}$-Vert are smaller than those of the sample Xylene-Fe- $800{ }^{\circ} \mathrm{C}$-Hor, the appearance of the part of thick fibers causes their specific surface area to be only $62 \mathrm{~m}^{2} / \mathrm{g}$. Their pore volume is also not large $\left(0.26 \mathrm{~cm}^{3} / \mathrm{g}\right)$ because of the same reason as that of the sample Xylene-Fe- $800{ }^{\circ} \mathrm{C}-\mathrm{Hor}$. The specific surface areas of the samples Propylene-Ni-750 ${ }^{\circ} \mathrm{C}$-Hor and Methane-Ni-650 ${ }^{\circ} \mathrm{C}$-Vert achieve $154 \mathrm{~m}^{2} / \mathrm{g}$ and $145 \mathrm{~m}^{2} / \mathrm{g}$, respectively, their pore volumes correspondingly increase greatly and reach $0.58 \mathrm{~cm}^{3} / \mathrm{g}$ and $0.54 \mathrm{~cm}^{3} / \mathrm{g}$, respectively, after oxidation with nitric acid. Their larger specific surface areas may be due to the removed amorphous carbon particles, their smaller diameters and fracture caused by oxidation on their surface.

Table 1

Porosity and specific surface areas of four kinds of the oxidized CNTs

\begin{tabular}{lcl}
\hline Sample no. & $S_{\text {BET }}\left(\mathrm{m}^{2} / \mathrm{g}\right)$ & $V_{\mathrm{p}}\left(\mathrm{cm}^{3} / \mathrm{g}\right)$ \\
\hline Xylene-Fe-800 ${ }^{\circ} \mathrm{C}-$ Hor & 47 & 0.18 \\
Benzene-Fe-1150 ${ }^{\circ} \mathrm{C}-$ Vert & 62 & 0.26 \\
Propylene-Ni-750 ${ }^{\circ} \mathrm{C}-$ Hor & 154 & 0.58 \\
Methane-Ni-650 ${ }^{\circ} \mathrm{C}-$ Vert & 145 & 0.54
\end{tabular}

$S_{\mathrm{BET}}=$ BET surface area; $V_{\mathrm{p}}=$ pore specific volume.

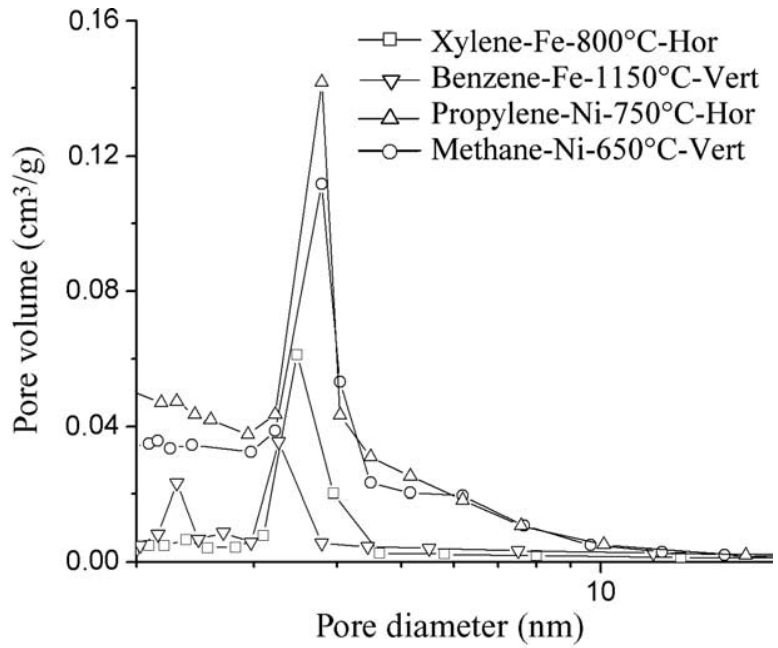

Fig. 2. Pore size distribution of four kinds of the oxidized CNTs.

Pore size distribution curves of four kinds of the oxidized CNTs are shown in Fig. 2. The mean pore diameter of the sample Xylene-Fe- $800{ }^{\circ} \mathrm{C}$-Hor is $3.4 \mathrm{~nm}$, while that of the sample Benzene-Fe- $1150{ }^{\circ} \mathrm{C}$-Vert is mainly distributed at 2.4 and $3.2 \mathrm{~nm}$. The mean pore diameters of the samples Propylene-Ni- $750{ }^{\circ} \mathrm{C}$-Hor and Methane-Ni- $650{ }^{\circ} \mathrm{C}$-Vert are $3.6 \mathrm{~nm}$. But their pore volumes are large to be compared with the samples Xylene-Fe- $800{ }^{\circ} \mathrm{C}-\mathrm{Hor}$ and Benzene-Fe$1150{ }^{\circ} \mathrm{C}$-Vert, which also suggests that the oxidation treatment can easily break up the CNTs with large amount of defects on their surfaces.

The particle size can affect the suspensibility and adsorption property of the adsorbents. The particle size distributions of four kinds of oxidized CNTs were characterized by laser light scattering analyzer (Fig. 3). The particle sizes of the sample Xylene-Fe- $800{ }^{\circ} \mathrm{C}$-Hor are mainly 30 and $570 \mu \mathrm{m}$. This is because that the CNTs of the sample Xylene-Fe- $800{ }^{\circ} \mathrm{C}$-Hor were produced on the quartz supporter and aligned in the form of arrays, and they are difficult to be scattered by the ball milling and oxidation treatments. For the sample Benzene-Fe- $1150{ }^{\circ} \mathrm{C}$-Vert, the thick fibers and the difficulty to fracture due to the higher

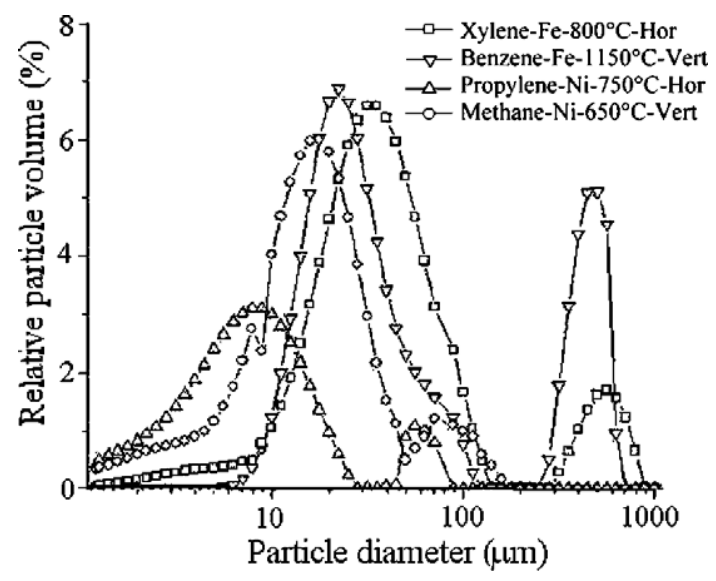

Fig. 3. Particle size distribution of four kinds of the oxidized CNTs. 
crystallizability degree make their particle size larger and distributed at 23 and $450 \mu \mathrm{m}$. The oxidation treatment can easily break up the CNTs into small pieces for the samples Propylene-Ni- $750{ }^{\circ} \mathrm{C}$-Hor and Methane-Ni- $650{ }^{\circ} \mathrm{C}$-Vert, so their particle size distributions decrease remarkably and spread at 8 and $55 \mu \mathrm{m}$ for the sample Propylene-Ni- $750^{\circ} \mathrm{C}$ Hor, 19 and $70 \mu \mathrm{m}$ for the sample Methane-Ni- $650{ }^{\circ} \mathrm{C}$-Vert.

Chemical oxidation of CNTs with nitric acid can introduce different acidic functional groups on their surfaces and thus improve their hydrophilic property and ionexchange property. In Table 2, the functional groups were quantitatively calculated by Boehm method. This method based on that sodium hydrogen carbonate only neutralizes carboxyl groups, sodium carbonate neutralizes carboxyl groups and lactones, sodium hydroxide can neutralize carboxyl groups, lactones and phenols. So the different kinds of functional groups can be calculated through the known volume of used acid and bases. The quantities of carboxyls and phenols on the surfaces of the CNTs abide by the following order: sample Methane-Ni- $650{ }^{\circ} \mathrm{C}$-Vert $>$ sample Propylene-Ni-750 ${ }^{\circ} \mathrm{C}$-Hor $>$ sample Xylene-Fe- $800{ }^{\circ} \mathrm{C}$ Hor $>$ sample Benzene-Fe- $1150{ }^{\circ} \mathrm{C}$-Vert. The sample Methane-Ni-650 ${ }^{\circ} \mathrm{C}$-Vert also has the maximum quantity of lactones and reaches $1.95 \mathrm{mmol} / \mathrm{g}$. Although the lactone quantity $(1.83 \mathrm{mmol} / \mathrm{g})$ of the sample Propylene-Ni- $750{ }^{\circ} \mathrm{C}-$ Hor is less than that of the Methane-Ni-650 ${ }^{\circ} \mathrm{C}$-Vert, it is greater than that of the samples Xylene-Fe- $800{ }^{\circ} \mathrm{C}$-Hor $(0.86 \mathrm{mmol} / \mathrm{g})$ and Benzene-Fe- $1150{ }^{\circ} \mathrm{C}-$ Vert $(0.93 \mathrm{mmol} /$ g). The result indicates that the curled CNTs with many defects on their surfaces (the samples Propylene-Ni- $750{ }^{\circ} \mathrm{C}$ Hor and Methane-Ni-650 ${ }^{\circ} \mathrm{C}$-Vert) can be introduced more functional groups than the straight ones (samples Xylene$\mathrm{Fe}-800{ }^{\circ} \mathrm{C}$-Hor and Benzene-Fe-1150 ${ }^{\circ} \mathrm{C}$-Vert).

The lead adsorption isotherms of four kinds of the oxidized CNTs with different morphologies are shown in Fig. 4. The lead adsorption capability of the sample Benzene-Fe- $1150{ }^{\circ} \mathrm{C}$-Vert is the weakest and their adsorption capacity is only $11.2 \mathrm{mg} / \mathrm{g}$ at the lead equilibrium concentration of $10 \mathrm{mg} / \mathrm{l}$. At the same conditions, the adsorption capacity of the sample Xylene-Fe- $800{ }^{\circ} \mathrm{C}-\mathrm{Hor}$ is $14.8 \mathrm{mg} / \mathrm{g}$. It improves greatly for the sample Propylene-Ni$750{ }^{\circ} \mathrm{C}-$ Hor and reaches $59.8 \mathrm{mg} / \mathrm{g}$. The sample MethaneNi-650 ${ }^{\circ} \mathrm{C}$-Vert has the maximum adsorption capability and its adsorption capacity increases to $82.6 \mathrm{mg} / \mathrm{g}$. The higher adsorption capability of the samples Propylene-Ni- $750{ }^{\circ} \mathrm{C}$ Hor and Methane-Ni- $650{ }^{\circ} \mathrm{C}$-Vert than that of the samples

Table 2

The amount of functional groups on the surfaces of four kinds of the oxidized CNTs determined by Boehm's method

\begin{tabular}{llll}
\hline Sample no. & $\begin{array}{l}\text { Carboxyl } \\
(\mathrm{mmol} / \mathrm{g})\end{array}$ & $\begin{array}{l}\text { Lactones } \\
(\mathrm{mmol} / \mathrm{g})\end{array}$ & $\begin{array}{l}\text { Phenols } \\
(\mathrm{mmol} / \mathrm{g})\end{array}$ \\
\hline Xylene-Fe-800 ${ }^{\circ} \mathrm{C}-\mathrm{Hor}$ & 0.27 & 0.86 & 0.50 \\
Benzene-Fe-1150 ${ }^{\circ} \mathrm{C}-$ Vert & 0.26 & 0.93 & 0.46 \\
Propylene-Ni-750 ${ }^{\circ} \mathrm{C}-\mathrm{Hor}$ & 0.76 & 1.83 & 1.45 \\
Methane-Ni-650 ${ }^{\circ} \mathrm{C}$-Vert & 0.85 & 1.95 & 1.51 \\
\hline
\end{tabular}

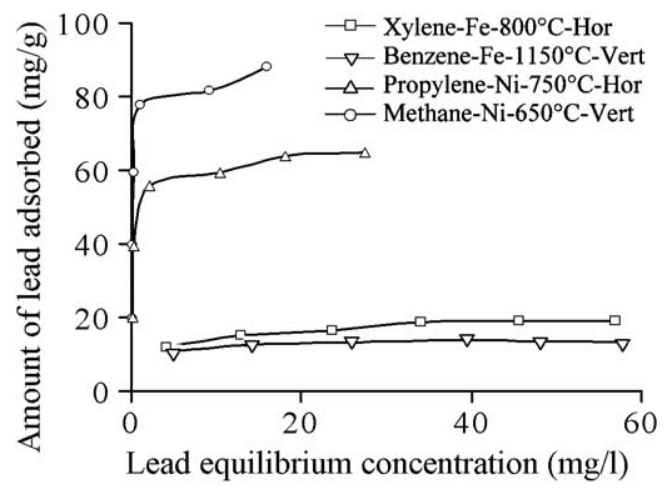

Fig. 4. Adsorption isotherms of lead adsorbed by four kinds of the oxidized CNTs (CNT dosage: $0.02 \mathrm{~g} / 100 \mathrm{ml}$; $\mathrm{pH}: 5.0$ ).

Xylene-Fe- $800{ }^{\circ} \mathrm{C}$-Hor and Benzene-Fe- $1150{ }^{\circ} \mathrm{C}$-Vert suggests that the larger specific surface area is available for the lead adsorption because it can increase the active adsorption sites on the surfaces of the CNTs. The more important reason for the improved adsorption capability of the samples Propylene-Ni-750 ${ }^{\circ} \mathrm{C}$-Hor and Methane-Ni-650 ${ }^{\circ} \mathrm{C}$-Vert is the large quantities of functional groups introduced on the surfaces of the CNTs by nitric acid oxidation (as shown in Table 2). The CNTs of the sample Methane-Ni- $650{ }^{\circ} \mathrm{C}$-Vert have many defects on their tops, the lateral surfaces and the curled places due to the lower preparation temperature (650 ${ }^{\circ} \mathrm{C}$ ) and large batch production $(500 \mathrm{~g} / \mathrm{batch})$, so although their specific surface area is smaller than that of the sample Propylene-Ni-750 ${ }^{\circ} \mathrm{C}-\mathrm{Hor}$, their functional groups on the surfaces are greater than those of the sample Propylene-Ni$750{ }^{\circ} \mathrm{C}$-Hor, thus they have the strongest lead adsorption capability than the other three kinds of CNTs. It can be concluded from the adsorption results that the more perfect morphologies of the CNTs possess, the lower adsorption capabilities they have.

\section{Conclusions}

Four kinds of CNTs with different morphologies were produced by chemical vapour deposition method and oxidized by concentrated nitric acid. The samples Propylene-Ni-750 ${ }^{\circ} \mathrm{C}$-Hor and Methane-Ni-650 ${ }^{\circ} \mathrm{C}$-Vert have higher specific surface area, more functional groups and smaller particle size distribution than the samples XyleneFe-800 ${ }^{\circ} \mathrm{C}$-Hor and Benzene-Fe- $1150{ }^{\circ} \mathrm{C}$-Vert. The lead adsorption isotherms show that the CNTs of the sample Methane-Ni-650 ${ }^{\circ} \mathrm{C}$-Vert have the maximum adsorption capability and their adsorption capacity reaches $82.6 \mathrm{mg} / \mathrm{g}$ at the lead equilibrium concentration of $10 \mathrm{mg} / \mathrm{l}$. At the same conditions, the adsorption capacity of sample Propylene-Ni$750{ }^{\circ} \mathrm{C}$-Hor is $59.8 \mathrm{mg} / \mathrm{g}$, while that of the samples XyleneFe- $800{ }^{\circ} \mathrm{C}$-Hor and Benzene-Fe- $1150{ }^{\circ} \mathrm{C}$-Vert is only 14.8 and $11.2 \mathrm{mg} / \mathrm{g}$, respectively. The adsorption results indicate that the CNTs with poor quality and morphology have higher lead adsorption capabilities. The exceptional adsorp- 
tion capability combined with large batch production of the sample Methane-Ni- $650{ }^{\circ} \mathrm{C}$-Vert makes the CNTs a promising material in environmental protection as adsorbent.

\section{References}

[1] M. Sekar, V. Sakthi, S. Rengaraj, Journal of Colloid and Interface Science 279 (2004) 307.

[2] A.N.A. El-Hendawy, S.E. Samra, B.S. Girgis, Colloids and Surfaces, A, Physicochemical and Engineering Aspects 180 (2001) 209.

[3] C. Liu, P.M. Huang, Geochimica et Cosmochimica Acta 67 (2003) 1045.

[4] W.C. Leung, H. Chua, W.H. Lo, Applied Biochemistry and Biotechnology 91 (2001) 171.

[5] B. Biskup, B. Subotic, Separation Science and Technology 39 (2004) 925.

[6] R. Sublet, M.O. Simonnot, A. Boireau, M. Sardin, Water Research 37 (2003) 4904.

[7] W. Chu, Water Research 33 (1999) 3019.

[8] X.M. Zhan, X. Zhao, A. Miyazaki, Y. Nakano, Chinese Journal of Chemical Engineering 11 (2003) 426.

[9] A. Javey, J. Guo, Q. Wang, M. Lundstrom, H.J. Dai, Nature 424 (2003) 654.

[10] W.A. deHeer, A. Chatelain, D. Ugarte, Science 270 (1995) 1179.

[11] J.M. Planeix, N. Coustel, B. Coq, V. Brotons, P.S. Kumbhar, R. Dutartre, P. Geneste, P. Bernier, P.M. Ajayan, Journal of the American Chemical Society 116 (1994) 7935.
[12] J. Kong, N.R. Franklin, C.W. Zhou, M.G. Chapline, S. Peng, K.J. Cho, H.J. Dai, Science 287 (2000) 622.

[13] A.B. Dalton, S. Collins, E. Munoz, J.M. Razal, V.H. Ebron, J.P. Ferraris, J.N. Coleman, B.G. Kim, R.H. Baughman, Nature 423 (2003) 703.

[14] Y. Wang, F. Wei, G.H. Luo, H. Yu, G.S. Gu, Chemical Physics Letters 364 (2002) 568.

[15] A.C. Dillon, K.M. Jones, T.A. Bekkedahl, C.H. Kiang, D.S. Bethune, M.J. Heben, Nature 386 (1997) 377.

[16] C.W. Bauschlicher, A. Ricca, Physical Review B 70 (2004) 115409.

[17] W.L. Yim, Z.F. Liu, Chemical Physics Letters 398 (2004) 297.

[18] M. Bienfait, P. Zeppenfeld, N. Dupont-Pavlovsky, M. Muris, M.R. Johnson, T. Wilson, M. DePies, O.E. Vilches, Physical Review B 70 (2004) 035410

[19] Y.H. Li, S. Wang, A. Cao, D. Zhao, X. Zhang, C. Xu, Z. Luan, D. Ruan, J. Liang, D. Wu, B. Wei, Chemical Physics Letters 350 (2001) 412.

[20] Y.H. Li, S. Wang, J. Wei, X. Zhang, C. Xu, Z. Luan, D. Wu, B. Wei, Chemical Physics Letters 357 (2002) 263.

[21] Y.H. Li, S. Wang, Z. Luan, J. Ding, C. Xu, D. Wu, Carbon 41 (2003) 1057.

[22] Y.H. Li, J. Ding, Z. Luan, Z. Di, Y. Zhu, C. Xu, D. Wu, B. Wei, Carbon 41 (2003) 2787.

[23] A.Y. Cao, L. Ci, G. Wu, B. Wei, C. Xu, J. Liang, D. Wu, Carbon 39 (2001) 152.

[24] L. Ci, Y. Li, B. Wei, J. Liang, C. Xu, D. Wu, Carbon 38 (2000) 1933.

[25] H.P. Boehm, Carbon 32 (1994) 759. 